\title{
Massive Open Online Course Platform Blended English Teaching Method Based on Model-View-Controller Framework
}

\author{
https://doi.org/10.3991/ijet.v14i16.11151 \\ Renfeng Wang \\ Yantai Nanshan University, Longkou, China \\ Wangrfe163.com
}

\begin{abstract}
Massive Open Online Course (MOOC) is an important tool to improve the autonomous learning of students and the teaching effects of the courses. Focusing on the online teaching of college English courses, this paper proposes a simple design of blended English teaching mode for the requirements of MOOC platform. Using the Model-View-Controller (MVC) framework and the Java programming language, the author realized the databaserelated functions of the platform by SQL server database, designed the backend server on the Spring and Hibernate integrated frameworks, and developed the entire platform using the browser/server $(\mathrm{B} / \mathrm{S})$ structure. The platform test results show that the MOOC-based blended English teaching mode satisfies the teaching demands, achieves stable performance, and wins the recognition of most students. The research findings shed new light on the innovation of college English teaching.
\end{abstract}

Keywords - Model-view-controller (MVC), massive open online course (MOOC), blended English teaching

\section{$1 \quad$ Introduction}

Under the background of global informationization, education informatization has become one of the main-streams of society. The use of Computer-Assisted Instruction (CAI) has been widely applied, and various online and interactive learning methods have also developed rapidly. MOOC is a new online course development mode that has emerged in recent years and is the product of Internet + education [1]. Although there are many open source platforms on the market, these open source platforms may not meet the actual needs of college English teaching. Therefore, in order to improve the effects of college English teaching, it is necessary to design and develop a MOOC teaching platform for college English, and study the blended teaching method of English MOOC in-depth. MOOC was originated in 2007 and widely recognized by the education community since 2012. Later, domestic and foreign scholars have analyzed the theory, origin and development of MOOC, MOOC-based blended teaching mode, the differences between MOOC and traditional teaching methods, and its characteris- 
tics, etc., they also discussed how MOOC serves the society and what impact does it bring to the education, and they have achieved a lot of research results [2]. In 2013, Tsinghua University adopted openedX-based source code to develop its own MOOC and officially launched Xuetangx.com. Although it's generally similar to edx in the technical aspect, the system has developed its own HTML5 video player [3]. The MOOC platform for Chinese universities icourse 163 launched by Netease cloud classroom is the most resourceful platform independently developed in the country, its system features are quite similar to Coursera [4]. As a language course, English focused more on practice and interaction. The open platform and a large number of teaching resources provided by MOOC can meet this requirement, allowing students to practice after the class and communicate in the language they have learned. Therefore, many universities at home and abroad have recognized the importance of MOOC environment in English teaching. The design, research and development of the college English teaching system under the MOOC environment has been put on the agenda by universities such as Shanghai Jiaotong University and Fudan University. Based on the above analysis, this paper adopted the MVC framework to study the design and implementation of the MOOC platform under the blended English teaching mode.

\section{MOOC-Based Blended English Teaching Method}

\subsection{Construction of blended English teaching mode}

Domestic and foreign scholars have not formed a unified concept about the blended teaching, but their general ideas are the same, in summary, it can be understood that blended teaching is based on the traditional teacher-led teaching mode, it integrates various flexible teaching methods, so that teachers can transform their roles from knowledge transferrers to the knowledge guiders, and students become the main body of learning. The whole learning process emphasizes the students' independent inquiry learning [5]. Therefore, the MOOC-based blended English teaching is a mix of the MOOC platform, the classroom teaching, and the teaching mode that based on different theoretical teachings [6].

Fig 1 shows the MOOC-based blended English teaching mode, which includes three parts: before class, classroom, and after school, and the learning evaluation runs through all links of the teaching mode [7]. Under this teaching mode, students become the main body of learning, their enthusiasm for learning has been improved, and they can exercise their autonomous learning ability.

- In the before-class learning stage, teachers provide students with relevant videos, audios, animation, texts, pictures and other learning materials on the MOOC platform according to the students' cognitive patterns, meanwhile, teachers assign learning discussion topics and relevant learning tasks to the students. Students learn by themselves and complete relevant exercises before the class, and teachers 
and students could discuss and communicate online about the questions the students encountered during the study.

- In the classroom teaching stage, teachers adopt appropriate teaching methods to explain the knowledge points involved in the topic according to the students' preclass learning situations. The students discuss the topics in groups and each group expresses its opinion, then teachers and students discuss and exchange about the topics, and teachers will review and summarize according to the discussion situation.

- During the after-school learning period, teachers summarize the classroom teaching effects, adjust the teaching methods, and conduct online communication with the students. Students complete the homework assignments and upload them according to the content of the classroom learning, and meanwhile they can continue to discuss online about the topics of the content they learnt and exchange their learning experiences.

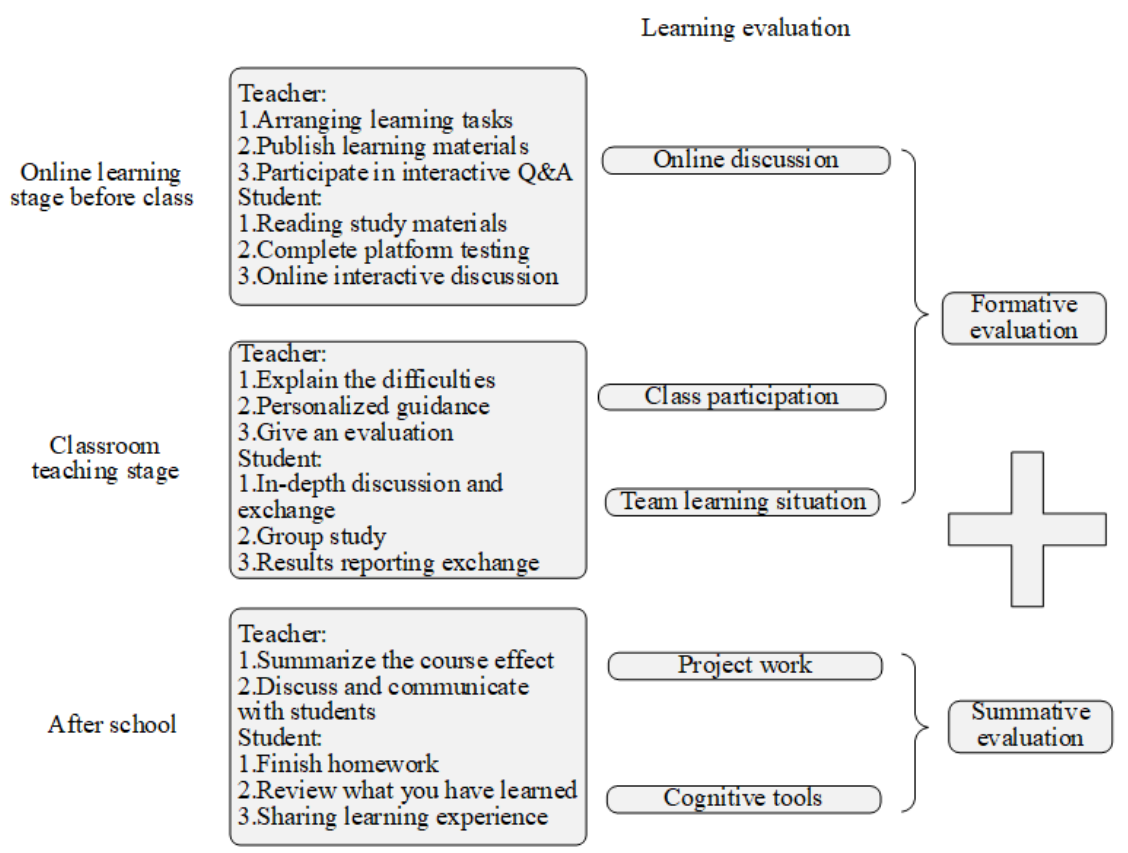

Fig. 1. MOOC-based blended English teaching mode

\subsection{Requirement analysis of the main functions of the platform}

According to the MOOC-based blended English teaching mode constructed above we can know that, the platform should have basic functions such as teaching resource sharing, interactive communication and discussion, job management and testing, etc. The primary responsibility of the system administrator is to maintain and manage the system. Students and teachers are the main users of the platform. The student users 
use the platform to conduct learning activities such as studying, testing and online discussion. The teachers use the platform to publish the relevant resources of the course teaching, interact with the students, and answer their questions. Fig 2 shows the specific function description of each user role on the platform.



Fig. 2. Specific function description of each user role on the platform

\section{Design and Implementation of MOOC Platform}

\subsection{Introduction to platform-related technologies}

MVC framework: MVC [8] is a software design paradigm, which is an abbreviation of Model-View-Controller. To avoid rewriting the business logic of the program, this design mode uses specialized component management business logic to separate the data processing and presentation of the program, and to separate the program control of input and output, it has the advantages of high efficiency, low coupling and repeatability.

Spring and hibernate frameworks: Spring [9] is a hierarchical JavaSE/EE fullstack lightweight open source framework that provides underlying transaction management and transaction abstraction management. The Spring MVC framework com- 
bines view technologies such as jquery, ajax, and jsp. Fig 3 shows the Spring MVC framework diagram. The Hibernate [10] framework is a fully automatic orm framework that automatically generates and executes SQL statements, it simplifies the developer's operation of the database. Hibernate performs lightweight object encapsulation on JDBC and can be applied to any occasion where JDBC is used.



Fig. 3. Spring MVC framework diagram

B/S structure: $\mathrm{B} / \mathrm{S}[11]$ structure is the browser/service mode. The main advantage of this mode is that users only need to install a browser on the client end to access related services of the platform, and the data interaction with the database is completed by the Web Server. This structure realizes zero-installation and zero-maintenance of the client end, its structure is shown as Fig 4, the proposed platform in this paper was develop using $\mathrm{B} / \mathrm{S}$ structure.

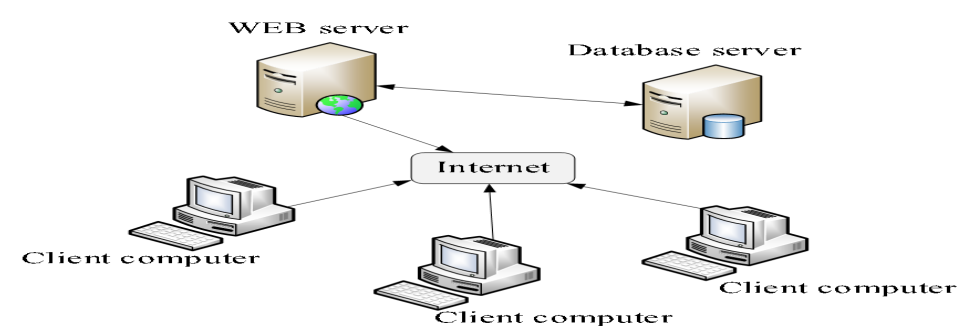

Fig. 4. B/S structure diagram

\subsection{Design and implementation of MOOC platform}

System function module design: Based on above requirement analysis of the main functions of the platform, compared with the design of other MOOC platforms, the proposed platform is divided into four functional modules of system management, teaching management (including resource management and evaluation), self-learning, and interactive learning according to the actual needs of blended English teaching, as shown in Fig 5. This paper mainly took the teaching management module and the interactive learning module as examples, and introduced their design and implementation in detail. 


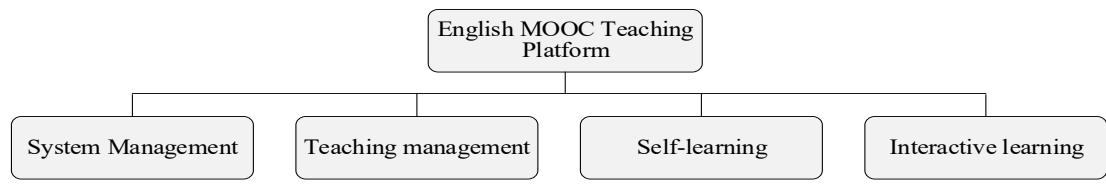

Fig. 5. MOOC English teaching platform function module diagram

Design and implementation of teaching management module: Teaching resource management, class management, course management and feedback evaluation management are the main components of the teaching management module. The course management mainly includes creating, modifying and deleting relevant course information. Teachers can use the teaching resource management module to edit course-related videos, audios, pictures, texts, test questions, and other teaching resources for students' pre-class preparation and after-class review. The teachers correct the student's homework through the evaluation feedback module, and analyze the student's test situation. The class management module is similar to the traditional class management function. Teachers can edit the class and student's personal information, and review the student's homework and test scores through the class management function.

Design and implementation of interactive learning module: The interactive learning module consists of three sub-modules, each of which has the following specific functions:

- Q\&A forum: Teachers and students can communicate and discuss with each other through the Q\&A forum, students can publish their learning feelings and experiences. Teachers can answer the questions encountered by the students in a timely manner, and adjust the teaching methods and contents according to the communication content. Students can also search for relevant posts in the past according to the classification, and find the answers to their own questions.

- Lecture hall: The main purpose of setting up a lecture hall is to improve the students' oral English levels. They can imitate the news reports or famous speeches in the lecture hall, and make speeches freely on discussion topics assigned by teachers, meanwhile they can use the recording function provided by the system to record their speech and upload it to the system for teachers and other students to watch and make comments.

- English corner module: Teachers and students can use English to chat online in the English Corner module to train students' ability to express in English. Teachers can also understand students' English proficiency during the chatting process and correct their errors. The module can also help teachers adjust their teaching plans.

Fig 6 shows the message interface of the Q\&A forum. Students can list the brief content of the question to be discussed as the titles, so that it's convenient for platform to classify and for other students to search. At the same time, the details can be input in the introduction and submitted, after other students or teachers see the post, they can reply it. 


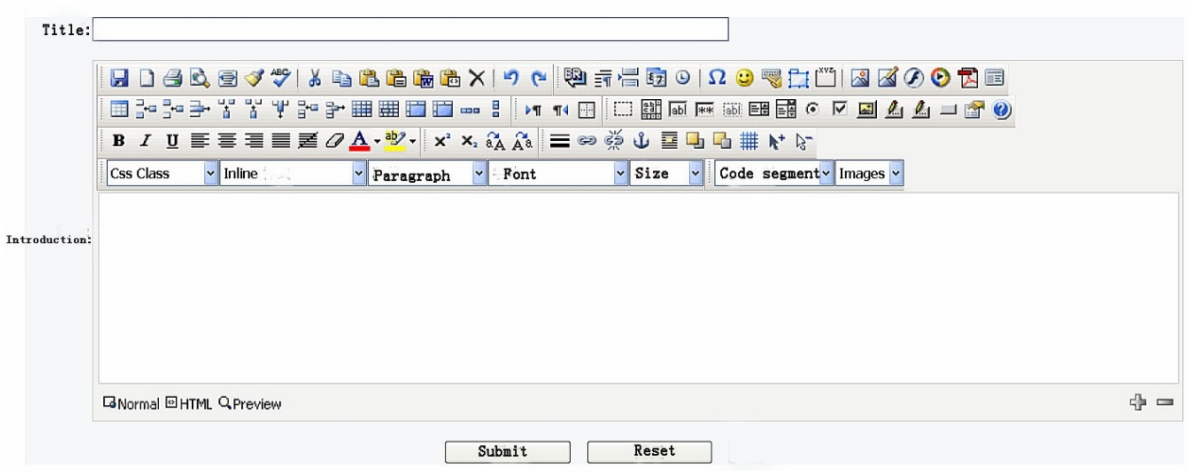

Fig. 6. Q\&A forum platform message interface

\subsection{Platform testing and teaching effects}

Platform test results: In order to ensure the practicability and operational reliability of the platform, we conducted relevant tests on the platform. The test results show that the platform interface's texts, size, layout, browser compatibility and other functions can meet the requirements. The editing, modifying, uploading and other related functions of each module can operate normally.

Whether the platform server can meet the requirement at the time when the concurrent is high is one of the important indicators for evaluating the performance of the system. Fig 7 shows the performance test results of the platform when simulating high concurrent access. It can be seen from the figure that as the number of users increases, memory usage grows slowly, and the average network utilization and CPU usage increase obviously, but not more than $55 \%$, which can still meet the basic requirements of users.

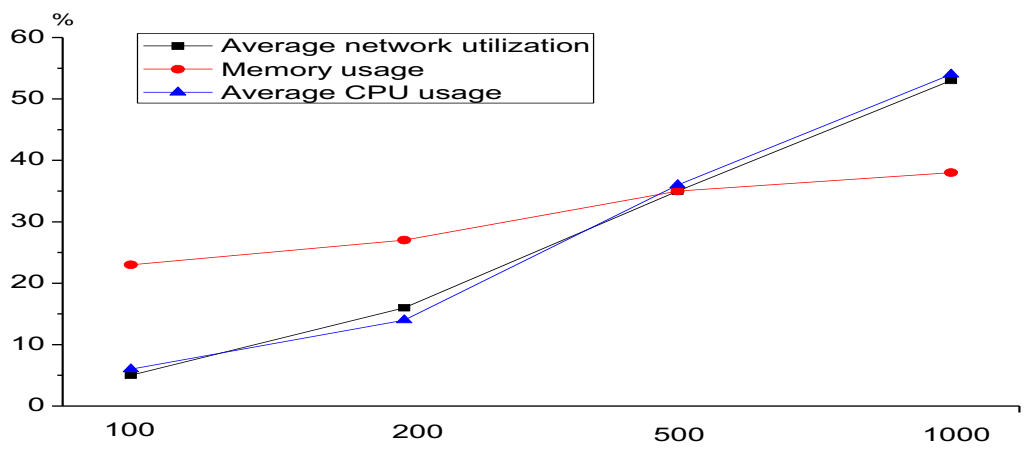

Fig. 7. Performance test results

Implementation evaluation of teaching effects: In order to test the learning effect of the MOOC-based blended English teaching mode, this paper selected 140 freshmen from a university who had participated in the MOOC-based blended English teaching 
as respondents, a total of 127 valid questionnaires were collected, and the effective rate was $100 \%$. It can be seen from the survey that $12 \%$ students are very satisfied with the teaching effects of the MOOC-based blended English teaching mode, 36\% are quite satisfied, and only $10 \%$ of the students are not satisfied. For these unsatisfied students, it's maybe because their computer operation skill is relatively poor or their English foundation is weak, and they cannot adapt to the new mode of blended teaching. The survey results indicate that the blended English teaching method based on the MOOC platform can effectively improve students' interest and learning effects.

\section{Conclusion}

This paper studied the MOOC platform blended English teaching method constructed based on MVC framework, and drew the following conclusions:

- This paper constructed a MOOC-based blended English teaching mode, and analyzed the requirements of the MOOC platform accordingly

- Using Spring and Hibernate integrated frameworks and B/S architecture technology, this paper designed the MOOC platform under the MVC framework

- The test results of the platform show that the platform has achieved the expected practicability and operational reliability. The evaluation results of the teaching effects show that most of the students are satisfied with the MOOC-based blended English teaching method.

\section{$5 \quad$ References}

[1] Li, R. H., Yu, J. X., Huang, X., Cheng, H., Shang, Z. (2014). Measuring the impact of mvc attack in large complex networks. Information Sciences, 278: 685-702. https://doi.org/10.1016/j.ins.2014.03.085

[2] Wu, H., Bailey, C., Rasoulinejad, P., Li, S. (2018). Automated comprehensive adolescent idiopathic scoliosis assessment using mvc-net. Medical Image Analysis, 48: 1-11. https://doi.org/10.1016/j.media.2018.05.005

[3] Konstan, J. A., Walker, J. D., Brooks, D. C., Brown, K., Ekstrand, M. D. (2015). Teaching recommender systems at large scale: evaluation and lessons learned from a hybrid mooc. ACM Transactions on Computer-Human Interaction (TOCHI), 22(2): 10. https://doi.org/10.1145/2728171

[4] Baggaley, J. (2014). Mooc postscript. Distance Education, 35(1): 126-132. https://doi.org/10.1080/01587919.2013.876142

[5] Boyle, J. (1997). The use of mixed-code in hong kong english language teaching. System, 25(1): 83-89. https://doi.org/10.1016/s0346-251x(96)00062-0

[6] Li, Y. (2018). Feature extraction and learning effect analysis for MOOCs users based on data mining, International Journal of Emerging Technologies in Learning, 13(10): 108120. https://doi.org/10.3991/ijet.v13i10.9456

[7] Freitas, S. I., Morgan, J., Gibson, D. (2015). Will moocs transform learning and teaching in higher education? Engagement and course retention in online learning provision. British Journal of Educational Technology, 46(3): 455-471. https://doi.org/10.1111/bjet.12268

[8] Shan, Y. P. (1989). An event-driven model-view-controller framework for smalltalk. Acm Sigplan Notices, 24(10): 347-352. https://doi.org/10.1145/74878.74913 
[9] Guichon, N. (2010). Preparatory study for the design of a desktop videoconferencing platform for synchronous language teaching. Computer Assisted Language Learning, 23(2): 169-182. https://doi.org/10.1080/09588221003666255

[10] Morris, N. (2012). Teaching as a design science: building pedagogical patterns for learning and technology by diana laurillard. British Journal of Educational Studies, 60(4): 448-450. https://doi.org/10.1080/00071005.2012.742279

[11] So, H. J., Lossman, H., Lim, W. Y., Jacobson, M. J. (2009). Designing an online videobased platform for teacher learning in singapore. Australasian Journal of Educational Technology, 25(3): 440-457. https://doi.org/10.14742/ajet.1144

\section{Author}

Renfeng Wang is a teacher of Yantai Nanshan University. She is currently in charge of the teaching and researching of College English Course. Her academic papers have been published on journal. One of papers has published on international conference proceeding. She has participated in the communication of instructional experience organized by Higher Education Press.

Article submitted 2019-05-29. Resubmitted 2019-07-15. Final acceptance 2019-07-17. Final version published as submitted by the authors. 